\title{
Examining Serendipitous Encounters and Self-Determination in Twitter-Enabled Innovation
}

\author{
Henri Pirkkalainen $\left(\mathbb{D},{ }^{1}\right.$ Ekaterina Olshannikova $\mathbb{D}^{2},{ }^{2}$ Thomas Olsson $\left(\mathbb{D},{ }^{2}\right.$ \\ and Jukka Huhtamäki $\mathbb{1}^{1}$ \\ ${ }^{1}$ Faculty of Management and Business, Tampere University, Korkeakoulunkatu 7, 33720 Tampere, Finland
${ }^{2}$ Faculty of Information Technology and Communication Sciences, Tampere University, Kalevantie 4, 33100 Tampere, Finland
}

Correspondence should be addressed to Henri Pirkkalainen; henri.pirkkalainen@tuni.fi

Received 26 November 2020; Accepted 5 May 2021; Published 18 May 2021

Academic Editor: Carmen Santoro

Copyright (C) 2021 Henri Pirkkalainen et al. This is an open access article distributed under the Creative Commons Attribution License, which permits unrestricted use, distribution, and reproduction in any medium, provided the original work is properly cited.

\begin{abstract}
Serendipity refers to unexpected encounters with ideas or insights and their intentional application to achieve favorable outcomes. Despite extensive prior studies, the concept lacks theoretical logic and empirical validation regarding the role of an intentional act in the relationship between serendipitous encounters and their favorable outcomes. Drawing from self-determination theory, we develop a model that highlights the role of needs satisfaction in explaining this relationship. Positioning the empirical context to fortunate discoveries of information and social connections in professional use of Twitter, we validate the model by a crosssectional survey study of 473 users. The model builds on the observation that individuals' serendipitous encounters are associated with Twitter-enabled innovation, that is, a contextualized form of task innovation. The study findings support the research model revealing that serendipitous encounters are positively associated with needs satisfaction and that needs satisfaction is positively associated with Twitter-enabled innovation. In other words, fortunate discoveries of new information and contacts increase Twitter users' intent to utilize the platform in new ways to accomplish work when the three key psychological needs of autonomy, competence, and relatedness are satisfied.
\end{abstract}

\section{Introduction}

In the organizational context, serendipity can be described as a fortunate discovery of new ideas, solutions, or insights, prompted by an individual's interaction with information, objects, or people $[1,2]$. Recent organizational research has highlighted the notion that also Twitter users experience serendipity [3-5]. They commonly use Twitter in search of profession-related information that can assist them in better performing their work [6]. They also engage in conversations on topics of professional interest in order to find new contacts and collaboration opportunities $[4,7,8]$. Researchers have suggested that Twitter-based accidental, though fortunate, discoveries of information and new contacts can facilitate task innovation in organizations $[5,7]$. Task innovation is defined as the extent to which the use of an IT application helps users create and try out new ideas in their work [9]. Examples of Twitter-based task innovation include increased personal productivity of knowledge workers via recommendations of digital tools by their early adopters of new technologies [5], new collaborative research and development projects via informal discussions with representatives from other industries [8], and expansion of business partnerships by engaging in discussions with weak ties via "contacts of contacts" [3]. Task innovation is considered a key factor in organizational success and competitive advantage [10-12].

Despite the apparent importance and potential association between serendipity and task innovation, literature on this topic is scarce. Researchers have argued that the accidental fortunate discovery of useful information and contacts, here referred to as a serendipitous encounter, does not automatically lead to favorable work-related outcomes; task innovation requires intentional act and effort to pursue new 
ways of applying this information and contacts in their daily practice $[5,9]$. Research on the concept of serendipity has also stressed the importance of understanding the association between fortunate discoveries (i.e., serendipitous encounters) and favorable outcomes, such as task innovation [11]. Interestingly, this line of research also posits that favorable outcomes should be coupled with the experience of serendipity and that serendipity requires deliberate effort at applying potentially useful fortunate discoveries in practice $[1,2,11]$, such as when individuals seek to do their jobs in new ways with the help of Twitter.

In other words, absent from the literature are the potential factors or mechanisms in explaining how favorable outcomes are enabled by the serendipitous encounters. To this end, the main research question for our study is "How does the aspect of intentional human behavior associate with serendipitous encounters and task innovation?"

To address the research question, we draw on self-determination theory (SDT) [13]. The theory posits that an individual's intent to pursue personal goals and reach favorable outcomes is enabled when their key needs are satisfied in the corresponding social environment [13], such as in the professional use of Twitter. Specifically, SDT considers the satisfaction of three fundamental individual needs: the need for autonomy is the experience of freedom and personal choice in one's actions; the need for competence is the experience of succeeding at challenging tasks; and the need for relatedness is the experience of mutual respect and reliance on others [14]. Individuals are likely to reach favorable outcomes when these three key needs are satisfied because they become more determined to pursue these outcomes [13]. The relevance of SDT has been proven in multiple organizational studies that have showcased increased job satisfaction, well-being, and productivity as resulting from high needs satisfaction $[15,16]$.

The related literature demonstrates two key insights that can help form the theoretical understanding of how needs satisfaction can account for the aspect of intent in the relationship between serendipity and task innovation. First, fortunate discoveries of new information and contacts encourage users to diversify the ways they use Twitter for work, such as developing their skills on how to use Twitter more effectively and reach out to further new contacts (e.g., $[5,7,8])$. Therefore, serendipitous encounters could support the satisfaction of the three needs depicted in SDT, thus creating a deliberate intent to pursue the serendipitous discoveries in their work. Second, prior research suggests that when dealing with complex organizational tasks, individuals deliberately pursue positive work outcomes, such as creativity and flexibility $[13,17]$, as a result of needs satisfaction. This study builds on these two key insights. A theoretical model is developed and consecutively validated in this study. The empirical investigation reports on a crosssectional online survey with 473 respondents who use Twitter for their work, and structural equation modeling is used to conduct the data analysis.

We make two key research contributions in this paper. First, we explain the importance of the satisfaction of individuals' psychological needs in the relationship between individuals' serendipitous encounters and task innovation. Through this, we enable a more comprehensive understanding of serendipity as a combination of an unexpected discovery of information and social connections and the selfdetermination to pursue the outcomes enabled by this discovery. Second, we validate the favorable effects of serendipitous encounters for work performance.

\section{Theoretical Background}

2.1. Serendipity in Organizations. Prior research has established that serendipity is a multifaceted concept and requires more than chance or luck $[1,9]$. Two related views have emerged suggesting it is necessary to extend the conceptual understanding of serendipity beyond chance and luck. The first view describes serendipity as an unexpected discovery of insights and ideas that an individual evaluates as useful $[11,18]$. This view holds that a serendipitous encounter is subjectively evaluated and that serendipity occurs as the individual identifies the usefulness of the unexpected insight for themselves. The second view holds that serendipity also calls for a prepared mind and engagement in follow-up activities to turn a happenstance into a valuable outcome $[1,2,11]$. As extension to the first view, the recognition of the importance of different unexpected events enables individuals to apply what they have discovered and to intentionally pursue the utilization of the discoveries in practice [2]. We subscribe to the latter view in this paper, meaning that the unexpected discoveries that an individual finds useful, referred to as a serendipitous encounter, and the pursuit to apply the discovery toward a favorable outcome are both included in the serendipity experience.

Serendipity has been primarily investigated in relation to unsought fortunate discoveries in information retrieval [19-21]. Here, serendipity is specifically examined from the perspective of encountering unexpected content or information that is perceived as beneficial. In this study, we refer to this perspective as information serendipity encounter, which arguably drives individual capacity building (e.g., knowledge acquisition) $[22,23]$ and fosters creativity in work-related tasks $[10,24]$. The fundamental premise is that new insights enable individuals to do their work better, such as solving problems more effectively $[1,25]$.

In addition to examining information serendipity encounters, studies have also addressed the interpersonal or social perspective. For example, research has focused on innovation processes [26], spontaneous encounters [27], and social awareness [28] in collocated work environments. Some studies have posited that physical and digital environments enable access to various information and engage interactions of diverse minds to achieve noticeable benefits in task innovation [29], thus increasing chances for serendipity to occur $[18,30]$. The literature on workplace knowledge-sharing suggests that new information and knowledge often emerge beyond an individual's closest connections or peers [31-33]. Recently, the concept of serendipity has gained interest in research on recommender systems [34, 35] and social connections [36, 37]. These studies place emphasis on encounters of unexpected, yet 
useful, new social connections (e.g., new collaborators) that are typically discovered based on social interactions around shared content [38]. In our study, we refer to these unexpected discoveries of new contacts as social serendipity encounters. Recent research has showed practical evidence of how unexpected, yet relevant, snippets of information or new social contacts can result in increased task performance [5].

2.2. Twitter Use in Organizations. Twitter use has broadened from social networking to professional use [7, 39]. With professional use, we specifically refer to cross-disciplinary use of Twitter for work-related communication. Information seeking (e.g., searching for content) and expertise seeking (e.g., searching for contacts) can be seen as two primary professional use purposes of Twitter [8]. Organizations also utilize Twitter for facilitating customer interactions to gain business value [40], and supporting employee professional development, that is, assisting them in acquiring new insights and skills [41]. Additionally, Twitter is commonly used during professional events as a mechanism to facilitate knowledge-sharing amongst the participants of a particular event $[42,43]$. Moreover, Twitter use can increase transparency of online knowledge-sharing behaviors in organizations [6].

Furthermore, Twitter has been widely used for knowledge work activities, such as distribution of information, accessing diverse information, utilizing online communities in ideation, and developing knowledge and skills [44-46]. From the perspective of the individual, Twitter allows professionals to express themselves beyond intraorganizational boundaries [7]. Employees use Twitter to discuss topics related to their profession and work tasks with people of diverse backgrounds and expertise [6], which helps in establishing informal networks [47] and collaboration opportunities $[6,8,48]$.

2.3. Twitter Use in Facilitating Serendipity. It has been argued that Twitter facilitates serendipity, which in turn positively affects users' engagement and social activities on the platform [49]. In particular, McCay-Peet and Quan-Haase [50] found that Twitter features and demographics enable users to perceive the platform as a serendipitous digital environment. Hashtags and links attached to tweets have been found to produce more opportunities for serendipitous encounters than stand-alone tweets [51]. Race and Makri [52] demonstrated how mentions, favorites, and retweets potentially trigger and facilitate serendipitous encounters.

We subscribe to the conceptualization of Martin and Quan-Haase [4] that digital environments like Twitter facilitate serendipitous encounters in two ways. First, Twitter is "trigger rich," meaning that the environment contains diverse information, ideas, and resources that are potentially interesting and relevant to the individual. Second, the user interface mechanisms of Twitter highlight new information and social connections via hashtags and recommendations, which can guide the user's attention in further exploring seemingly interesting content.
To the best of our knowledge, no prior research has explicitly focused on serendipity in the professional use of Twitter. This topic has mainly been acknowledged in related studies, though not empirically investigated. For instance, Bogers and Björneborn [53] noted that a subset of their study sample experienced work-related serendipity on Twitter. Piao [51] suggested that the multifaceted use of Twitter for both leisure and professional purposes is likely to result in serendipitous experiences. Although the theoretical understanding of serendipity in the professional use of Twitter remains limited, there is plenty of empirical evidence to suggest its prevalence. For example, it has been established that the use of microblogging in work enables serendipity [8]. Twitter allows users to gain an understanding of what others are working on and inspires them to look for information and contacts they would not otherwise pursue. This is primarily due to the public nature of Twitter content: one does not need to know their contacts or their expertise beforehand; instead, the activities and conversations on Twitter can lead them to the trail of potentially useful information and contacts, even beyond the users they are currently following.

2.4. Self-Determination Theory. Self-determination theory posits that individuals pursue personal goals and self-growth to the extent that they perceive their psychological needs are satisfied [54]. The satisfaction of the three fundamental psychological needs of autonomy, competence, and relatedness is relevant for knowledge work activities that are handled both online and offline [13, 54]. Research has investigated needs satisfaction in association with employees' engagement in organizational tasks [14] as well as their performance at work [15]. Studies have also established the importance of the three needs in the nonwork use of information systems, such as health management systems [55], knowledge-sharing sites [56], and video games [57]. The effects of high needs satisfaction have been shown to increase job satisfaction, well-being, and productivity $[15,16]$. Although positive outcomes have been established, not all activities provide the same opportunities to satisfy needs [13]. For example, activity that is enabled by an information system that has no features for social interaction is unlikely to satisfy a user's need for relatedness because the user has limited options to interact and have a sense of connection with others.

Twitter use for work arguably offers an opportunity for overall needs satisfaction: (1) Twitter use is autonomous and intentional because its extensity is mainly enabled by users' interest in the activity itself (using Twitter to support work) [8]; (2) the effective use of Twitter for work is highly dependent on users' capability to integrate Twitter use in their work activities $[5,8]$. As Twitter can be applied in different ways, users' skills, and their corresponding perception of the challenges of Twitter use, can vary; (3) Twitter is widely used for professional networking, and in nonwork settings, it has been shown to satisfy the need for relatedness [58]. Thus, it can fulfil the need for autonomy (e.g., freedom to use Twitter how one prefers), competence (e.g., capability to use Twitter 
effectively), and relatedness (e.g., caring for individuals who one spends time with on Twitter). We now propose a model that explains the relevance of these three concepts in relation to the professional use of Twitter.

\section{Research Model for Understanding Serendipity in the Professional Use of Twitter}

Our serendipity model on the professional use of Twitter is shown in Figure 1. It draws from the conceptual understanding of serendipity $[2,11]$-the need for individual effort in making sense of how unexpected encounters can be applied to achieve positive outcomes. The effect of serendipitous encounters on task innovation, that is, Twitterenabled innovation, serves as the basis of the study. The model includes individual self-determination, that is, needs satisfaction [13], as a key factor in explaining deliberate behavior to strive toward a favorable outcome. We now illustrate the associations between the specific constructs of the model.

\subsection{Hypothesizing How Fortunate Discoveries Lead to Task} Innovation. Prior research has established that individuals use IT applications, such as Twitter, to find new insights that could be applied to their work [5, 7, 8]. Making use of such insights in work is referred to as task innovation $[10,12]$. Individuals who use IT applications for this reason apply the ideas that they come across online [10]. Research suggests that this step would not be possible without the identification of new insights or information [59]. For instance, Twitter users often share ideas emanating from their work with other professionals; for example, software developers often share newly developed code, and analysts share methods that allow them to make sense of data in new ways; knowledge workers share potentially useful management techniques they have gleaned from books, podcasts, etc. Moreover, Twitter serves as an index to other social media and digital services, including blogs, code repositories, and question-answer services. The novelty of the ideas, however, is often explored in conversations emerging around tweets. Within such conversations and explorations of tweets, users may encounter meaningful insights for their work. The identification of unexpected information that the individual evaluates as valuable is, essentially, a serendipitous encounter.

Although the identification of information and the application of that information can take place simultaneously, the management literature acknowledges that, in terms of task innovation, they are indeed separate, as the application requires the use of the information or insight to solve a particular work task $[10,60]$. This understanding aligns with that of serendipity. Specifically, the core tenet of the serendipity experience is the identification of potentially useful insights that are applied to solve a pressing problem or to advance a current way of working (e.g., $[1,11])$. Our model posits that, in the context of professional Twitter use, serendipitous encounters lead to Twitter-enabled innovation. Organizational examples point to the benefits of fortunate discoveries of content and social connections. Fortunate discoveries at the content level enable individuals to view their work in a new light [5]. Individuals must attend to follow-up activities to apply new insights to the problems encountered in their work $[1,11]$. Such experience of discovery is positive and represents a strong predictor of valuable outcomes in organizations [61], such as venture success [10, 62]. Fortunate discoveries of contacts (e.g., experts with whom to collaborate) are imperative for task innovation because the application of new insights in organizations is dependent on social processes, such as collaboration between professionals [63]. Thus, we posit that the identification of valuable information and new contacts permits their application, instantiated through the use of Twitter to aid their work. Thus, we posit the following hypothesis.

Hypothesis 1. (H1): Serendipitous encounters are positively associated with Twitter-enabled innovation.

3.2. Hypothesizing How Serendipitous Encounters Fuel Needs Satisfaction. Building on the prior work covered in Section 2, our model posits that information and social serendipity encounters in Twitter help satisfy the three needs. Fortunate discoveries of information are known to encourage individuals $[8,18]$. When users identify new insights or contacts that are beneficial and relevant to their work, their doubts are relieved in regard to the benefits of carrying out the activity, such as using Twitter for ongoing work tasks $[8,50]$. This can foster needs satisfaction on three levels. First, individuals can be encouraged because they gain new insights and contacts on their own terms [8], thus, increasing the sense of autonomy for their work-related use of Twitter. Second, realizing the usefulness of the newly found information and contacts builds their confidence in their own competence regarding the use of Twitter for work [8]. Third, such useful insights and contacts help individuals develop a sense of belonging, or relatedness, to the social network, which is essential for creating bonds and engaging in further social interaction $[5,8]$. Thus, our model posits the following.

Hypothesis 2. (H2) : Serendipitous encounters are positively associated with needs satisfaction.

As indicated in our literature review, autonomous employees use Twitter intentionally to find information and talent beyond their own organizations [3, 5]. Employees' competence has been observed in their capability to assimilate information from Twitter and to make use of it for the benefit of their organization [64]. Employees who have been able to innovate through Twitter have also been found to care for their newly established contacts and intentionally seek long-lasting interpersonal relationships [5]. Indeed, self-determined individuals have been observed to be effective at utilizing new ideas at work [65]. This suggests that higher levels of needs satisfaction can lead to innovation at work among Twitter users. Our model depicts that individuals' encounters of unexpected information and contacts 


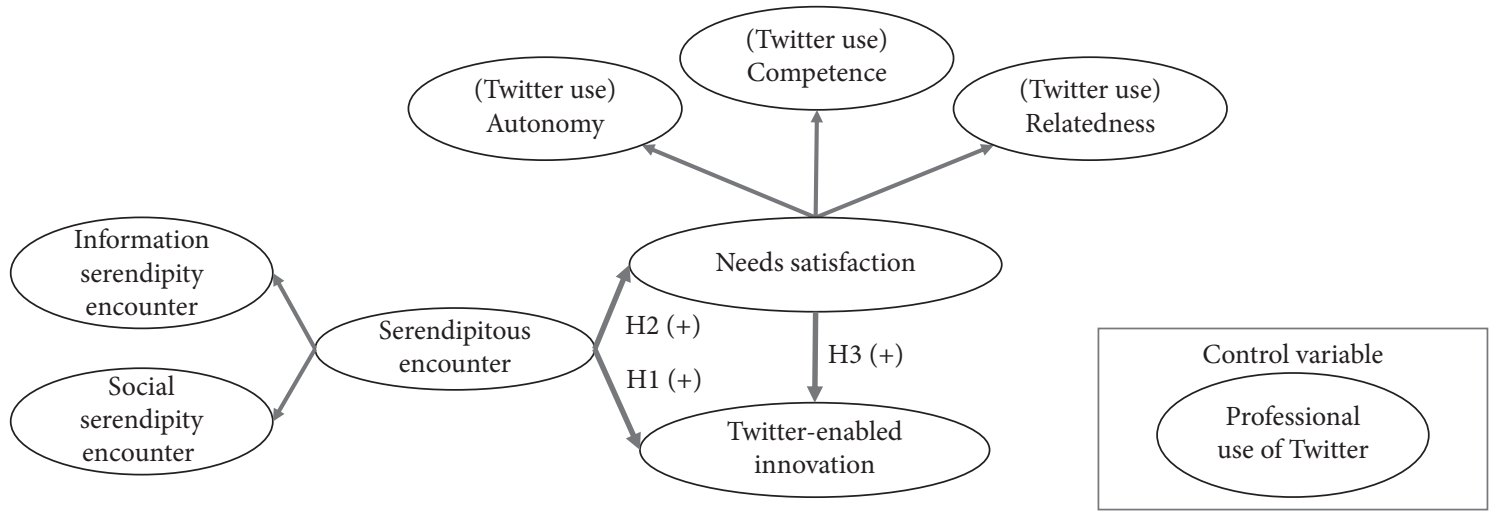

FIgURE 1: Serendipity model in the professional use of Twitter.

enable them to find meaning in their use of Twitter for work in a way that their key needs are satisfied in the context of Twitter use. This enables increased determination toward using Twitter purposefully for work, which enables task innovation. This leads us to the following hypothesis.

Hypothesis 3. (H3): Needs satisfaction is positively associated with Twitter-enabled innovation.

Based on the insights from self-determination theory and the reviewed serendipity literature, our model also suggests that none of these encounters and outcomes are possible without the use of Twitter for professional purposes. This is so for two reasons. First, serendipity [1], needs satisfaction [54], and task innovation [9] are each based on individual activity, meaning that the individual expends effort in actualizing them (e.g., by using Twitter). Second, online social environments, such as Twitter, have significant influence on users' abilities to assimilate and apply information [10]. For these reasons, we investigate the construct of "professional use of Twitter" as a control variable in the study. This additional factor can help us account for the effect of work-related use of Twitter on task innovation and the experience of serendipity. Furthermore, demographic factors will be examined to account for their potential effects on the dependent variables.

\section{Method}

4.1. Data Collection. The data used to validate our model were collected via an online survey. As our study is focused on professional use of Twitter, we were specifically interested in individuals who use Twitter for their work. We did not want to limit our study to certain professions or industries. Instead, we invited part- or full-time employees in various occupations to study their experiences of serendipity, task innovation, and needs satisfaction. We utilized the service of Prolific, a UK-based company with access to a panel of Twitter users. Although their panel mainly consists of UK citizens, it also includes members from across Europe, the US, and Asia. The use of online panels has two main benefits. It allows the collection of cross-sectional data and enables full anonymity of respondents $[66,67]$.
To ascertain whether the respondents used Twitter for their work, we requested that Prolific screen their panel for eligible individuals who (1) worked in part- or full-time positions and (2) used Twitter for work (e.g., to support work tasks or professional networking) on a daily, weekly, or monthly basis. The respondents who fulfilled these two criteria were invited to participate in the study. Moreover, we included further survey questions on the professional use of Twitter to ensure that the respondents matched our target population.

We collected a total of 546 responses in our survey. The data were screened in multiple steps. First, we tackled unconscious responding by removing responses that had no or very little standard deviation across the study indicators $(<0.5$, on a seven-step scale; $1=$ strongly disagree to $7=$ strongly agree). Second, we removed potentially fake answers that could be identified in open text fields (e.g., giving unrelated and inappropriate comments). Third, we removed responses that were submitted suspiciously quickly, i.e., in less than three minutes. On average, filling in the survey took nine minutes. Finally, 473 responses were included in the study. The sample demographics are presented in Table 1.

4.2. Measures. All the constructs in our study were adapted from existing and validated scales. The Twitter-enabled innovation scale was adjusted from the task innovation scale by Torkzadeh and Doll [9], which we adjusted to the context of Twitter use. We chose the online serendipity scale by Lutz et al. [18], because of its emphasis on the unexpected encounter of information. Moreover, consistent with our chosen conceptualization of serendipity, it also includes the extent to which individuals find that particular information useful. The original scale captures an encounter of information serendipity, which is why we adjusted it to the context of Twitter, as well as an encounter of social serendipity, based on prior findings (e.g., [4]). The two conceptually cognate perspectives on serendipitous encounters, information and social, were then treated as a second-order construct, labeled as serendipitous encounter. Needs satisfaction consisted of three constructs depicted in SDT [13], namely, (perceived) autonomy, (perceived) competence, and 
TABLE 1: Sample characteristics $(N=473)$.

\begin{tabular}{|c|c|c|}
\hline Variable & Category & Frequency \\
\hline \multirow{2}{*}{ Gender } & Female & $200(43 \%)$ \\
\hline & Male & $272(57 \%)$ \\
\hline \multirow{3}{*}{ Age } & $18-35$ years & $29362 \%)$ \\
\hline & $36-50$ years & $152(32 \%)$ \\
\hline & $51-67$ years & $28(6 \%)$ \\
\hline \multirow{4}{*}{ Nationality } & $\mathrm{UK}$ & $276(58 \%)$ \\
\hline & Rest of Europe & $88(19 \%)$ \\
\hline & US & $91(19 \%)$ \\
\hline & Other ( $<6$ respondents per country) & $18(4 \%)$ \\
\hline \multirow{7}{*}{ Education } & Less than high school & $4(1 \%)$ \\
\hline & Graduated high school & $57(12 \%)$ \\
\hline & Trade/technical school & $19(4 \%)$ \\
\hline & Some college, no degree & $64(14 \%)$ \\
\hline & Associate degree & $24(5 \%)$ \\
\hline & Bachelor's degree & $191(40 \%)$ \\
\hline & Advanced degree (master's, Ph.D., M.D.) & $113(24 \%)$ \\
\hline \multirow{9}{*}{ Industry } & Financial services/sales & $85(17.97 \%)$ \\
\hline & ICT & $76(16.07 \%)$ \\
\hline & Education & $53(11.21 \%)$ \\
\hline & Architecture/logistics/infrastructure & $40(8.46 \%)$ \\
\hline & Media/entertainment & $37(7.82 \%)$ \\
\hline & Healthcare/medical/pharmaceutical & $28(5.92 \%)$ \\
\hline & Business services & $27(5.71 \%)$ \\
\hline & Manufacturing & $24(5.07 \%)$ \\
\hline & $\begin{array}{c}\text { Other, }<5 \% \text { each (government, biotechnologies, marketing, aerospace, research, food services, } \\
\text { agriculture, etc.) }\end{array}$ & $\begin{array}{c}103 \\
(21.78 \%)\end{array}$ \\
\hline \multirow{5}{*}{ Position/job title } & Manager & $140(30 \%)$ \\
\hline & Professional & $132(28 \%)$ \\
\hline & Administrative/support personal & $90(19 \%)$ \\
\hline & Top level executive & $58(12 \%)$ \\
\hline & Other, $<5 \%$ each (business owner, researcher, architect, freelancer, assistant, driver, editor, etc.) & $53(11 \%)$ \\
\hline \multirow{4}{*}{$\begin{array}{l}\text { Twitter use experience in } \\
\text { years }\end{array}$} & Less than a month & $9(2 \%)$ \\
\hline & Less than a year & $54(11 \%)$ \\
\hline & $1-4$ years & $242(51 \%)$ \\
\hline & More than 4 years & $168(36 \%)$ \\
\hline
\end{tabular}

(perceived) relatedness. It was operationalized as a secondorder construct with three first-order constructs, similar to Deci et al. [14] and Assadi and Hassanein [55]. The firstorder scales were adjusted from the work of Partala [68] to reflect the use of Twitter for work. All the items were measured on a Likert-scale ranging from 1 (strongly disagree) to 7 (strongly agree), except for the Twitter use scale, which measured frequency of use ranging from 1 (never) to 5 (every time). The items of the study are presented in Table 2.

\section{Data Analysis and Results}

We used the SPSS software (version 25) to prepare the data and AMOS (version 25.0.0) to examine the indicator and construct reliabilities. We estimated the model by using structural equation modeling.

5.1. Indicator and Construct Reliability and Validity. The reliability and validity of the model indicators were analyzed using standardized confirmatory factor analysis (CFA) loadings. Most of the item loadings (17/21, Table 2) were greater than 0.700 , the threshold suggested by Chin [69], whereas the lowest loading was 0.574 . We did not remove any items from the scales, as factor loadings greater than 0.400 have been considered acceptable in prior IS research [70]. Further, we evaluated the reliabilities and validities of the model constructs. The composite reliability of each construct was greater than 0.80 (up to 0.96), which exceeds the recommended 0.70 threshold suggested by Fornell and Larcker [71]. Further, the average variance extracted (AVE) of each construct in the model was greater than 0.58 (up to 0.92), which exceeds the suggested 0.50 threshold [71]. Finally, we assessed whether the square root of AVE was greater than or equal to its correlation with the other model constructs. All the constructs of the model met this criterion. This supports the reliability and validity of both the model indicators and constructs (see Table 3 for further details).

Further, we tested for potential common method variance (CMV) in the model indicators and for common method bias (CMB) in the model estimates. First, we tested for potential CMV with Harman's one-factor test [72]. This 
TABle 2: Items, standardized CFA loadings, means, and standard deviations.

\begin{tabular}{|c|c|c|c|}
\hline Item wording & Loading & Mean & $\mathrm{Sd}$ \\
\hline \multicolumn{4}{|l|}{ Twitter-enabled innovation (TI) } \\
\hline TI1 using Twitter helps me to identify innovative ways of doing my job & $0.835 * * *$ & 4.890 & 1.408 \\
\hline TI2 using Twitter helps me to come up with new ideas related to my job & $0.798 * * *$ & 5.070 & 1.327 \\
\hline TI3 using Twitter helps me to try out innovative ideas in my job & $0.794 * * *$ & 4.910 & 1.371 \\
\hline \multicolumn{4}{|l|}{ Information serendipity encounter (IS) } \\
\hline IS1 when using Twitter, I have made an accidental fortunate discovery of content that was useful for me & $0.799 * * *$ & 5.190 & 1.340 \\
\hline IS2 when using Twitter, I have made an unexpected fortunate discovery of content that was useful for me & $0.771 * * *$ & 5.160 & 1.372 \\
\hline IS3 when using Twitter, I have encountered useful information, ideas, or resources that I was not looking for & $0.711 * * *$ & 5.410 & 1.202 \\
\hline \multicolumn{4}{|l|}{ Social serendipity encounter (SS) } \\
\hline SO1 when using Twitter, I have made an accidental fortunate discovery of a contact that was useful for me & $0.864 * * *$ & 5.080 & 1.366 \\
\hline SO2 when using Twitter, I have made an unexpected fortunate discovery of a contact that was useful for me & $0.833 * * *$ & 5.040 & 1.376 \\
\hline SO3 when using Twitter, I have encountered useful contacts that I was not looking for & $0.758 * * *$ & 5.160 & 1.318 \\
\hline \multicolumn{4}{|l|}{ Twitter use autonomy (TUA) } \\
\hline TUA1 I feel that my choices (e.g., who I decide to follow) are based on my true interests and values on Twitter & $0.669 * * *$ & 5.170 & 1.258 \\
\hline TUA2 I feel free to do things my own way on Twitter & $0.614 * * *$ & 5.190 & 1.276 \\
\hline TUA3 I feel that my choices (e.g., who I decide to follow) express my "true self" on Twitter & $0.765 * * *$ & 4.710 & 1.381 \\
\hline \multicolumn{4}{|l|}{ Twitter use competence (TUC) } \\
\hline TUC1 I feel that I am successfully completing difficult tasks and projects on Twitter & $0.792 * * *$ & 4.320 & 1.499 \\
\hline TUC2 I feel that I am taking on and mastering hard challenges on Twitter & $0.743 * * *$ & 4.020 & 1.570 \\
\hline TUC3 I feel very capable in what I do on Twitter & $0.574 * * *$ & 5.400 & 1.166 \\
\hline \multicolumn{4}{|l|}{ Twitter use relatedness (TUR) } \\
\hline TUR1 I feel a sense of contact with people who care for me and whom I care for on Twitter & $0.860 * * *$ & 4.410 & 1.509 \\
\hline TUR2 I feel close and connected with other people who are important to me on Twitter & $0.797 * * *$ & 4.600 & 1.539 \\
\hline TUR3 I feel a strong sense of intimacy with the people I spend time with on Twitter & $0.794 * * *$ & 3.820 & 1.669 \\
\hline \multicolumn{4}{|l|}{ Professional use of Twitter (PRO) } \\
\hline PRO1 I use Twitter to support my work activities & $0.848 * * *$ & 3.860 & 1.000 \\
\hline PRO2 I use Twitter in my work & $0.763 * * *$ & 3.770 & 1.132 \\
\hline PRO3 I use Twitter to support professional networking & $0.667 * * *$ & 3.660 & 1.074 \\
\hline
\end{tabular}
$* * * p<0.01$.

TABLE 3: Cross-construct correlations.

\begin{tabular}{lcccccccc}
\hline & CR & AVE & Age & Gender & SDT & SER & USE & TI \\
\hline Age & 1.00 & 1.00 & SIC & & & & & \\
Gender & 1.00 & 1.00 & 0.008 & SIC & & & & \\
SDT & 0.899 & 0.748 & 0.022 & 0.091 & 0.865 & & & \\
SER & 0.961 & 0.925 & -0.034 & 0.013 & 0.410 & 0.962 & & \\
USE & 0.805 & 0.582 & 0.096 & 0.023 & 0.453 & 0.355 & 0.763 & \\
TI & 0.850 & 0.655 & 0.011 & 0.038 & 0.745 & 0.603 & 0.587 & 0.809
\end{tabular}

Note: diagonal axis presents the square root of the AVE, construct reliability (CR), and single-item construct (SIC), SDT: needs satisfaction, SER: serendipitous encounter, USE: professional use of twitter, TI: Twitter-enabled innovation.

was done by running an exploratory factor analysis (EFA, maximum likelihood, varimax rotation) in SPSS with one general factor. According to this test, CMV is a potential issue if one general factor accounts for the majority of the covariance amongst the model indicators [72]. We observed that CMV was likely not an issue because the single factor accounted for $37 \%$ of the variance, which is below the generally agreed $50 \%$ threshold. Second, we tested for potential CMB with the CFA marker variable approach [73] by introducing a theoretically unrelated fashion-consciousness construct (e.g., [74]). We prepared two models for comparison. The first included the proposed research model. The second included the research model with an uncorrelated fashion-consciousness construct. We compared the models with each other and observed only minor differences in the model estimates. Based on these two separate tests, we observed that neither CMV nor CMB was a likely concern for the study.

5.2. Model Estimation. We evaluated the model fit against several goodness of fit statistics before proceeding to estimate the research model. We selected both absolute (SRMR, RMSEA) and relative (e.g., CFI, TLI, GFI) fit indices, as they enable a comprehensive evaluation of goodness of fit [75]. Table 4 presents the goodness of fit values according to the cut-off criteria suggested by $\mathrm{Hu}$ and Bentler [76], Gefen et al. [77], and Kline [78]. As shown in Table 4, the values clearly supported the goodness of the model fit with the data, allowing us to proceed with the model estimation.

The results of the model estimation are provided in Figure 2. They denote the standardized effects and their statistical significance $(* * * p<0.001)$ as well as the proportion of the variance explained $\left(R^{2}\right)$ in the "needs satisfaction" and "Twitter-enabled innovation" constructs. Each of the theorized effects were found to be statistically significant. (1) Specifically, the serendipitous encounters of Twitter users (both information and social encounters) had a positive effect $(0.307 * * *)$ on Twitterenabled innovation, providing support for Hypothesis 1 . This suggests that Twitter users who were successful in finding new ways to handle their work with the help of Twitter had perceived higher amounts of serendipity 
TABLE 4: Goodness of fit statistics.

\begin{tabular}{lccccccc}
\hline$\chi^{2}$ & $\mathrm{df}$ & $\chi^{2} / \mathrm{df}$ ratio & CFI & TLI & GFI & SRMR & RMSEA \\
\hline 462,918 & 177 & $2.6\left(\chi^{2} / \mathrm{df}<3.0\right)$ & $0.94(\mathrm{CFI} \geq 0.90)$ & $0.93(\mathrm{TLI} \geq 0.90)$ & $0.91(\mathrm{GFI} \geq 0.90)$ & $0.06($ SRMR $\leq 0.08)$ & $0.06(\mathrm{RMSEA} \leq 0.06)$ \\
\hline
\end{tabular}

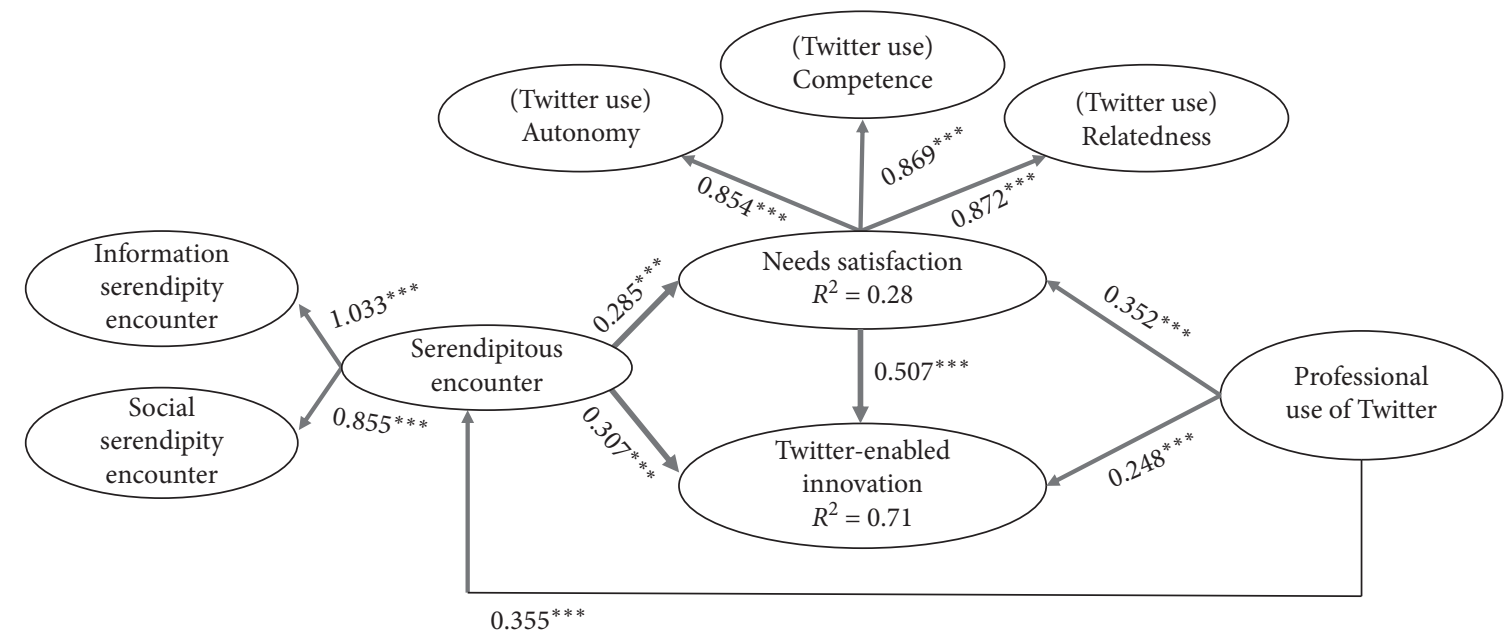

Figure 2: Model results $(* * * p<0.001)$.

encounters. Further, the serendipitous encounters of Twitter users had a positive effect $(0.285 * * *)$ on needs satisfaction (formed by Twitter use autonomy, competence, and relatedness), providing support for Hypothesis 2 . This suggests that the level of self-determination was higher for individuals who perceived higher number of information and social serendipity encounters on Twitter. The effect of needs satisfaction on Twitter-enabled innovation was similarly found positive and statistically significant $(0.507 * * *)$, providing support for Hypothesis 3. This finding suggests that Twitter users who were successful in innovating in their work with the help of Twitter perceived higher levels of self-determination, as in the notion that they had developed strong intent to benefit from Twitter use in their work. Thus, the model was well supported by the survey data. In terms of the proportion of the variance explained, the model explains $28 \%$ of the variance in needs satisfaction and $71 \%$ in Twitter-enabled innovation.

In regard to the control variable, the findings show that professional Twitter use has a positive and significant effect on serendipity $(0.355, p<0.001)$, needs satisfaction $(0.352, p<0.001)$, and Twitter-enabled innovation $(0.248$, $p<0.001)$. These findings confirm prior research findings that serendipity experience [1], needs satisfaction [54], and task innovation [9] are all subject to individuals' efforts within the social environment. Several post-hoc analyses were conducted to examine the effects of the demographic variables on the dependent variables. The findings show that male respondents perceived higher needs satisfaction on Twitter use $(0.96 * *)$ than females, high education was associated with high perceived level of Twitter-enabled innovation $(0.104 * *)$, and a generalized linear model analysis indicated that Twitter- enabled innovation also depends on the job position of the respondent $(p<0.006)$. For instance, the analysis indicated that respondents in manager roles perceived higher levels of Twitter-enabled innovation $($ mean $=5.21$ on a scale from 1, indicating a strong disagreement with the statement, to 7 , indicating a strong agreement), than administrative and support personnel (mean $=4.59$ ).

\section{Discussion and Conclusions}

The study focused on serendipity in the context of the professional use of Twitter. Prior research has suggested the importance of serendipitous encounters for individual task innovation and organizational performance. We extend this theoretical understanding by theorizing and empirically validating a model that explains how individuals reach favorable outcomes with the help of self-determination. The implications of our findings are discussed next.

6.1. Research Contributions. This study makes two key contributions to research. First, we show the importance of the satisfaction of individuals' psychological needs in the relationship between their serendipitous encounters and task innovation. Prior studies have argued for the necessity of an intentional act: the deliberate application of serendipitous discoveries in practice (e.g., $[2,11])$. However, these studies have not provided a conceptual explanation of how this intent plays a part in the relationship of serendipity encounters and their favorable outcomes, neither have they demonstrated which factors could explain this empirically. With the help of self-determination theory, we proposed that the intentional act to pursue the discoveries in practice is enabled by higher levels of determination, a critical aspect of 
human motivation [13]. Specifically, we show that serendipitous encounters aid the satisfaction of the key needs, which in turn has a positive association with task innovation in the context of work-related use of Twitter. Our model and the findings enable a more comprehensive understanding of serendipity as a combination of the unexpected discovery of information and contacts and the self-determination required to boost the user's intent to pursue the outcomes enabled by this discovery. This combination is essential because it offers a holistic and nuanced view of the serendipity experience. The high explanatory power of the model (71\% of the variance in Twitter-enabled innovation) highlights its relevance in relation to the professional use of Twitter.

We would also like to stress that the satisfaction of key psychological needs is critical to achieving task innovation in organizations. This is an important business factor because the systems and applications used in organizations often cross organizational boundaries, enabling organizations to bridge their work with those of others. Such a business factor can only be enabled in the context of individuals and their self-determination. To the best of our knowledge, this is the first study of the SDT perspective in the context of the professional use of Twitter. With SDT, we also account for individuals' perception of their Twitter use (i.e., IT use autonomy, competence, and relatedness) and extend this understanding as an essential channel for organizations and for the study of serendipity.

Second, our study empirically validates the favorable effects of serendipity experiences in work performance. We specifically illustrate that (1) serendipity is positively associated with Twitter-enabled innovation, that is, task innovation through the use of Twitter, and (2) needs satisfaction is positively associated with Twitter-enabled innovation, meaning that this positive outcome is more likely achieved when psychological needs are satisfied. These findings add the missing ingredient of human psychology (i.e., needs satisfaction) to the previously suggested effect of serendipitous encounters on task innovation [5]. The findings also add to the current understanding of idea generation and idea implementation-two highly related concepts that have remained largely disconnected in prior research $[10,59]$. Thus, our model explains the beneficial nature of fortunate discoveries of information and contacts on Twitter in performing work with the help of Twitter.

Furthermore, a post-hoc analysis indicated several interesting effects of the demographic variables on the dependent variables. Although the data at hand does not explain why males in our sample perceived higher levels of autonomy, competence, and relatedness on work-related use of Twitter, it is possible that the finding is related to satisfaction, preferences of use, and even work-related aspirations. Similarly, the current dataset does not explain why more highly educated respondents in higher positions were more likely to find new ways of utilizing Twitter in their work. It is possible that their motives for using Twitter are different and that the use is goal-oriented. Further research is required to explain the observed differences.
6.2. Practical Contributions. The results of this study can inform organizations and individuals who utilize Twitter for work purposes. We argue for the importance of serendipity experiences in task innovation. Because the use of Twitter and innovating with it both require individual effort, we encourage organizations to consider the potential of Twitter as an essential channel for work. Favorable outcomes are less likely reached when one or more of the following three factors are compromised.

First, the employee must have the freedom to decide how they use Twitter for work. Here, we emphasize that, in many cases, this would not jeopardize organizational strategy. We suggest that organizations need to reexamine their strategy to include Twitter use. We do acknowledge the limitations of Twitter use when truly sensitive data might leak to competitors. However, the literature notes multiple cases of major companies using Twitter for network building, without going into specifics regarding their organizational processes. Thus, employees should still have room to discuss issues about their work or profession without major organizational risks.

Second, employees must be able to build their competencies in how they apply Twitter for work. Here, organizations will not necessarily need to act on it because Twitter has a plethora of functionalities to achieve information retrieval and networking for various purposes. Thus, mastering Twitter for work is a highly individual issue. However, we do wish to point out the possibility of organizational training programs on the effective use of Twitter. Best practices from within and outside the company can give individuals mental models for using Twitter's opportunities in a holistic manner.

Third, employees must have opportunities to build workrelated relationships on Twitter. This objective is in line with current organizational trends. Organizations increasingly support the emergence of informal social connections both within and between organizations. Thus, organizational structures and boundaries are becoming more flexible and dynamic, supporting professional digital interaction between knowledge workers. We encourage organizations to support their employees in forming new social connections independently and point to Twitter for a concrete tool to do so.

6.3. Limitations and Future Research. Studying work-related IT use experiences (e.g., serendipity) on dynamic and multipurpose platforms, such as Twitter, is methodologically challenging, which sets limitations for the study. One limitation was the study sample: instead of having a balanced country representation, it was largely based on respondents from one country, the UK. However, seeking assistance from a UK-based company, despite the uneven sample, ensured that the respondents used Twitter for work and, thus, were suitable participants for the study. Another limitation was that we measured task innovation as a self-reported measure of Twitter-enabled innovation. We acknowledge that objective measures of task performance may give more accurate estimates on the outcomes of serendipitous encounters. Thus, future research can also examine other 
organizational outcomes of Twitter use, such as team performance or personal productivity.

Additionally, we did not account for personality factors. We believe that it is important to take factors such as big five personality traits (i.e., Neuroticism, Extraversion, Openness to Experience, Agreeableness, and Conscientiousness) [79] into account in future research because they are likely to add to the understanding of serendipity experiences. Although prior research has highlighted personalized recommendations and related factors in enabling serendipity (e.g., $[21,35])$, we believe that it would be fruitful to examine technology-related characteristics (e.g., push notifications, invasiveness) as facilitators of professional Twitter use and serendipity experiences. Furthermore, future research could investigate factors that may hinder the outcomes of serendipitous encounters, including organizational factors (e.g., IT use restrictions). These aforementioned factors and aspects of satisfaction with work-related uses of Twitter might be fruitful in explaining the observed gender difference in regard to the needs satisfaction on Twitter. Finally, we call for further empirical research to test the model in other contexts where serendipity typically occurs. Broadening the research to other social media platforms is highly encouraged from the perspectives of validation of the findings of this study and to account for new insights on work-related aspects of serendipity.

Given the limited research on the professional use of Twitter, this article shows the importance of needs satisfaction in the interplay of factors relating to the identification (i.e., serendipitous encounters) and utilization (i.e., task innovation) of work-related insights. We hope that this paper sparks interest in developing a theoretical understanding of serendipity experiences relating to the professional use of Twitter. We believe that this topic is critical, as more organizations approach Twitter as a strategic communication tool.

\section{Data Availability}

The underlying survey data can be obtained upon request from the corresponding author.

\section{Conflicts of Interest}

The authors declare that they have no conflicts of interest.

\section{Acknowledgments}

This work was conducted under Business Finland Project Big Match (3166/31/2017 and 3074/31/2017).

\section{References}

[1] M. P. E. Cunha, "Serendipity: why some organizations are luckier than others," FEUNL Working Paper Series No. 472, Universidade Nova de Lisboa, Lisbon, Portugal, 2005.

[2] M. De Rond, "The structure of serendipity," Culture and Organization, vol. 20, no. 5, pp. 342-358, 2014.

[3] L. Dantonio, S. Makri, and A. Blandford, "Coming across academic social media content serendipitously," Proceedings of the American Society for Information Science and Technology, vol. 49, no. 1, pp. 1-10, 2012.

[4] K. Martin and A. Quan-Haase, "A process of controlled serendipity": an exploratory study of historians' and digital historians' experiences of serendipity in digital environments," Proceedings of the Association for Information Science and Technology, vol. 54, no. 1, pp. 289-297, 2017.

[5] S. Parise, E. Whelan, and S. Todd, "How Twitter users can generate better ideas," MIT Sloan Management Review, vol. 56, no. 4, pp. 21-25, 2015.

[6] W. Van Zoonen, J. W. M. Verhoeven, and R. Vliegenthart, "How employees use Twitter to talk about work: a typology of work-related tweets," Computers in Human Behavior, vol. 55, pp. 329-339, 2016.

[7] M. H. Jarrahi, "Social media, social capital, and knowledge sharing in enterprise," IT Professional, vol. 20, no. 4, pp. 37-45, 2018.

[8] D. Zhao and M. B. Rosson, "How and why people Twitter: the role that micro-blogging plays in informal communication at work," in Proceedings of the ACM 2009 International Conference on Supporting Group Work - GROUP '09, pp. 243-252, ACM Press, Sanibel Island, FL, USA, May 2009).

[9] G. Torkzadeh and W. J. Doll, "The development of a tool for measuring the perceived impact of information technology on work," Omega, vol. 27, no. 3, pp. 327-339, 1999.

[10] N. Anderson, K. Potočnik, and J. Zhou, "Innovation and creativity in organizations: A state-of-the-science review, prospective commentary, and guiding framework," Journal of Management, vol. 40, no. 5, pp. 1297-1333, 2014.

[11] L. McCay-Peet and E. G. Toms, "Investigating serendipity: how it unfolds and what may influence it," Journal of the Association for Information Science and Technology, vol. 66, no. 7, pp. 1463-1476, 2015.

[12] J. Harvey, E. Lefebvre, and L. Lefebvre, "Technology and the creation of value in services: a conceptual model," Technovation, vol. 13, no. 8, 1993.

[13] M. Gagné and E. L. Deci, "Self-determination theory and work motivation," Journal of Organizational Behavior, vol. 26, no. 4, pp. 331-362, 2005.

[14] E. L. Deci, R. M. Ryan, M. Gagné, D. R. Leone, J. Usunov, and B. P. Kornazheva, "Need satisfaction, motivation, and wellbeing in the work organizations of a former eastern bloc country: a cross-cultural study of self-determination," Personality and Social Psychology Bulletin, vol. 27, no. 8, pp. 930-942, 2001.

[15] P. P. Baard, E. L. Deci, and R. M. Ryan, "Intrinsic need satisfaction: a motivational basis of performance and weilbeing in two work Settings," Journal of Applied Social Psychology, vol. 34, no. 10, pp. 2045-2068, 2004.

[16] W.-T. Wang and Y.-P. Hou, "Motivations of employees' knowledge sharing behaviors: a self-determination perspective," Information and Organization, vol. 25, no. 1, pp. 1-26, 2015.

[17] R. Koestner and G. F. Losier, "Distinguishing three ways of being highly motivated: a closer look at introjection, identification, and intrinsic motivation," in Handbook of Self-Determination Research, E. L. Deci and R. M. Ryan, Eds., pp. 101-121, University of Rochester Press, Rochester, NY, USA, 2002.

[18] C. Lutz, C. Pieter Hoffmann, and M. Meckel, "Online serendipity: a contextual differentiation of antecedents and outcomes," Journal of the Association for Information Science and Technology, vol. 68, no. 7, pp. 1698-1710, 2017. 
[19] A. Foster and N. Ford, "Serendipity and information seeking: an empirical study," Journal of Documentation, vol. 59, no. 3, pp. 321-340, 2003.

[20] K. Martin and A. Quan-Haase, "Are e-books replacing print books? tradition, serendipity, and opportunity in the adoption and use of e-books for historical research and teaching," Journal of the American Society for Information Science and Technology, vol. 64, no. 5, pp. 1016-1028, 2013.

[21] A. Quan-Haase and L. McCay-Peet, "The new boundaries of search-Serendipity in digital environments," in Die Googleisierung der Informationssuche-Suchmaschinen zwischen Nutzung und Regulierung, B. Stark, D. D. örr, and S. Aufenanger, Eds., pp. 135-158, O'Reilly, Newton, MA, United States, 2014.

[22] I. Buchem, "Serendipitous learning: recognizing and fostering the potential of microblogging," Open Journal per la formazione in rete, vol. 11, no. 74, pp. 7-16, 2011.

[23] J. E. Nutefall and P. M. Ryder, "The serendipitous research process," The Journal of Academic Librarianship, vol. 36, no. 3, pp. 228-234, 2010.

[24] M. E. D. Koenig, "Why serendipity is the key to innovation," Knowledge Management Review, vol. 3, no. 2, pp. 11-12, 2000.

[25] L. McCay-Peet and E. G. Toms, "The Process of Serendipity in Knowledge Work," in Proceeding of the Third Symposium on Information Interaction in Context - IIiX '10, pp. 377-382, New Brunswick, NJ, USA, August 2010.

[26] V. L. Rubin, J. Burkell, and A. Quan-Haase, "Facets of serendipity in everyday chance encounters: a grounded theory approach to blog analysis," Information Research, vol. 16, no. 3, 2011.

[27] S. Kiesler and J. N. Cummings, "What do we know about proximity and distance in work groups? A Legacy of Research," Distributed Work, pp. 57-80, MIT Press, Cambridge, MA, USA, 2002.

[28] D. Vyas, A. Dix, and G. C. van der Veer, "Reflections and encounters: exploring awareness in an academic environment," Computer Supported Cooperative Work (CSCW), vol. 24, no. 4, pp. 277-317, 2015.

[29] S. Johnson, Where Good Ideas Come from: The Natural History of Innovation, Penguin Books Limited, London, UK, 2010.

[30] L. McCay-Peet and E. G. Toms, Researching Serendipity in Digital Information Environments, Morgan and Claypool Publishers, San Rafael, CA, USA, 2017.

[31] R. S. Burt, Structural Holes: The Social Structure of Competition, Harvard Business Press, Cambridge, MA, USA, 1992.

[32] I. Leftheriotis and M. N. Giannakos, "Using social media for work: losing your time or improving your work?" Computers in Human Behavior, vol. 31, pp. 134-142, 2014.

[33] S. Rodan and C. Galunic, "More than network structure: how knowledge heterogeneity influences managerial performance and innovativeness," Strategic Management Journal, vol. 25, no. 6, pp. 541-562, 2004.

[34] P. Adamopoulos and A. Tuzhilin, "On unexpectedness in recommender systems: or how to better expect the unexpected," ACM Transactions on Intelligent Systems and Technology (TIST), vol. 5, no. 4, p. 54, 2015.

[35] M. Kunaver and T. Požrl, "Diversity in recommender systems-a survey," Knowledge-Based Systems, vol. 123, pp. 154-162, 2017.

[36] T. Olsson, J. Huhtamäki, and H. Kärkkäinen, "Directions for professional social matching systems," Communications of the $A C M$, vol. 63, no. 2, pp. 60-69, 2020.
[37] N. Eagle and A. Pentland, "Social serendipity: mobilizing social software," IEEE Pervasive Computing, vol. 4, no. 2, pp. 28-34, 2005.

[38] J. M. Mayer, Q. Jones, and S. R. Hiltz, "Identifying opportunities for valuable encounters: Toward context-aware social matching systems," ACM Transactions on Information Systems, vol. 34, no. 1, pp. 1-32, 2015.

[39] C. Honeycutt and S. C. Herring, "Beyond microblogging: conversation and collaboration via Twitter," in Proceedings of the 42nd Hawaii International Conference on System Sciences2009, pp. 1-10, IEEE Computer Society, Waikoloa, HI, USA, January 2009.

[40] M. J. Culnan, P. J. Mchugh, J. I. Zubillaga, M. Q. Uarterly, and E. Xecutive, "How large US companies can use Twitter and other social media to gain business value," MIS Quarterly Executive, vol. 9, no. 4, pp. 243-259, 2010.

[41] J. P. Carpenter and D. G. Krutka, "How and why educators use Twitter: a survey of the field," Journal of Research on Technology in Education, vol. 46, no. 4, pp. 414-434, 2014.

[42] H. Aramo-Immonen, J. Jussila, and J. Huhtamäki, "Exploring co-learning behavior of conference participants with visual network analysis of Twitter data," Computers in Human Behavior, vol. 51, pp. 1154-1162, 2015.

[43] W. Reinhardt, M. Ebner, G. Beham, and C. Costa, "How people are using Twitter during conferences," in Proceedings of the 5th EduMedia Conference, pp. 145-156, Salzburg, Austria, January 2009.

[44] E. K. Choo, M. L. Ranney, T. M. Chan et al., "Twitter as a tool for communication and knowledge exchange in academic medicine: a guide for skeptics and novices," Medical Teacher, vol. 37, no. 5, pp. 411-416, 2015.

[45] L. I. Hitchcock and A. Battista, "Social media for professional practice: integrating Twitter with social work pedagogy," Journal of Baccalaureate Social Work, vol. 18, no. 1, pp. 33-45, 2013.

[46] J. Priem and K. L. Costello, "How and why scholars cite on Twitter," Proceedings of the American Society for Information Science and Technology, vol. 47, no. 1, pp. 1-4, 2010.

[47] H. S. Risser, "Virtual induction: a novice teacher's use of Twitter to form an informal mentoring network," Teaching and Teacher Education, vol. 35, pp. 25-33, 2013.

[48] A. El Ouirdi, M. El Ouirdi, J. Segers, and E. Henderickx, "Employees' use of social media technologies: a methodological and thematic review," Behaviour and Information Technology, vol. 34, no. 5, pp. 454-464, 2015.

[49] T. Sun, M. Zhang, and Q. Mei, "Unexpected relevance: an empirical study of serendipity in retweets," in Seventh International AAAI Conference on Weblogs and Social Media, Cambridge, MA, USA, June 2013.

[50] L. McCay-Peet and A. Quan-Haase, "The influence of features and demographics on the perception of twitter as a serendipitous environment," in Proceedings of the 27th ACM Conference on Hypertext and Social Media, pp. 333-335, ACM, Halifax, Nova Scotia, Canada, July 2016.

[51] S. Piao and J. Whittle, "A feasibility study on extracting twitter users' interests using NLP tools for serendipitous connections," in Proceedings of the IEEE Third International Conference on Privacy, Security, Risk and Trust (PASSAT) and the 2011 IEEE Third International Conference on Social Computing (SocialCom), pp. 910-915, IEEE, Boston, MA, USA, October 2011.

[52] Elsevier, Accidental Information Discovery: Cultivating Serendipity in the Digital Age, T. M. Race and S. Makri, Eds., Elsevier, London, UK, 2016. 
[53] T. Bogers and L. Björneborn, Micro-serendipity: Meaningful Coincidences in Everyday Life Shared on Twitter, iSchools, Fort Worth, TX, USA, 2013.

[54] R. Ryan and E. Deci, "Self-determination theory and the facilitation of intrinsic motivation, social development, and well-being," The American Psychologist, vol. 55, no. 1, pp. $68-78,2000$.

[55] V. Assadi and K. Hassanein, "Consumer adoption of personal health record systems: a self-determination theory perspective," Journal of Medical Internet Research, vol. 19, no. 7, pp. 1-19, 2017.

[56] Y. Lee, J. Lee, and Y. Hwang, "Relating motivation to information and communication technology acceptance: selfdetermination theory perspective," Computers in Human Behavior, vol. 51, pp. 418-428, 2015.

[57] R. M. Ryan, C. S. Rigby, and A. Przybylski, "The motivational pull of video games: a self-determination theory approach," Motivation and Emotion, vol. 30, no. 4, pp. 347-363, 2006.

[58] G. M. Chen, "Tweet this: a uses and gratifications perspective on how active Twitter use gratifies a need to connect with others," Computers in Human Behavior, vol. 27, no. 2, pp. 755-762, 2011.

[59] T. M. Amabile, Creativity in Context: Update to the Social Psychology of Creativity, Hachette, London, UK, 1996.

[60] A. Van de Ven, "Central problems in the management of innovation," Management Science, vol. 32, pp. 590-607, 1986.

[61] F. Yuan and R. W. Woodman, "Innovative behavior in the workplace: the role of performance and image outcome expectations," Academy of Management Journal, vol. 53, no. 2, pp. 323-342, 2010.

[62] R. A. Baron and J. Tang, "The role of entrepreneurs in firmlevel innovation: joint effects of positive affect, creativity, and environmental dynamism," Journal of Business Venturing, vol. 26, no. 1, pp. 49-60, 2011.

[63] J. Rank, N. E. Nelson, T. D. Allen, and X. Xu, "Leadership predictors of innovation and task performance: subordinates' self-esteem and self-presentation as moderators," Journal of Occupational and Organizational Psychology, vol. 82, pp. 465-489, 2009.

[64] E. Whelan, S. Parise, J. De Valk, and R. Aalbers, "Creating employee networks that deliver open innovation," MIT Sloan Management Review, vol. 53, no. 1, p. 37, 2011.

[65] J. Knol and R. Van Linge, "Innovative behaviour: the effect of structural and psychological empowerment on nurses," Journal of Advanced Nursing, vol. 65, no. 2, pp. 359-370, 2009.

[66] B. Bulgurcu, H. Cavusoglu, and I. Benbasat, "Information security policy compliance: an empirical study of rationalitybased beliefs and information security awareness," MIS Quarterly, vol. 34, no. 3, pp. 523-548, 2010.

[67] P. B. Lowry, J. D’Arcy, B. Hammer, and G. D. Moody, "Cargo Cult" science in traditional organization and information systems survey research: a case for using nontraditional methods of data collection, including Mechanical Turk and online panels," Journal of Strategic Information Systems, vol. 25, no. 3, pp. 232-240, 2016.

[68] T. Partala, "Psychological needs and virtual worlds: case second life," International Journal of Human Computer Studies, vol. 69, no. 12, pp. 787-800, 2011.

[69] W. W. Chin, "Commentary: issues and opinion on structural equation modeling," MIS Quarterly, vol. 22, no. 1, 1998.

[70] D. Gefen, D. W. Straub, and M.-C. Boudreau, "Structural equation modeling and regression: guidelines for research practice," Communications of the Association for Information Systems, vol. 4, 2000.
[71] C. Fornell and D. F. Larcker, "Evaluating structural equation models with unobservable variables and measurement error," Journal of Marketing Research (JMR), vol. 18, no. 1, pp. 39-50, 1981.

[72] P. M. Podsakoff and D. W. Organ, "Self-reports in organizational research: problems and prospects," Journal of Management, vol. 12, no. 2, pp. 531-544, 1986.

[73] M. K. Lindell and D. J. Whitney, "Accounting for common method variance in cross-sectional research designs," Journal of Applied Psychology, vol. 86, no. 1, pp. 114-121, 2001.

[74] N. K. Malhotra, S. S. Kim, and A. Patil, "Common method variance in IS research: a comparison of alternative approaches and a reanalysis of past research," Management Science, vol. 52, no. 12, pp. 1865-1883, 2006.

[75] D. Hooper, J. Coughlan, and M. R. Mullen, "Structural equation modelling: guidelines for determining model fit," The Electronic Journal of Business Research Methods, vol. 6, no. 1, pp. 53-60, 2008.

[76] L. T. Hu and P. M. Bentler, "Cutoff criteria for fit indexes in covariance structure analysis: conventional criteria versus new alternatives," Structural Equation Modeling: A Multidisciplinary Journal, vol. 6, no. 1, pp. 1-55, 1999.

[77] D. Gefen, D. W. Straub, and E. E. Rigdon, "An update and extension to SEM guidelines for administrative and social science research," Management Information Systems Quarterly, vol. 35, no. 2, 2011.

[78] R. B. Kline, Principles and Practice of Structural Equation Modeling, Guilford Press, New York, NY, USA, 2nd ed. edition, 2005.

[79] P. T. Costa and R. R. McCrae, The NEO Personality Inventory Manual, Psychological Assessment Resources, Odessa, FL, USA, 1985. 